\title{
Algunas cuestiones sobre la aprobación de los tratados en la reforma constitucional de 2005
}

\section{I.- Introducción}

La reforma constitucional del ańo 2005, por la ley 20.050, tuvo su fundamento en dos mociones y un veto presidencial. Estimamos que esta reforma conticne un interesante material de estudio en relación a los tratados, pues hace alusión a varias instituciones que en la antigua norma no se consideraban.

Como las normas son genéricas, hay mucho espacio para la interpretación, y a medida que la práctica vaya entregando discintas hipótesis, se irá entiqueciendo el espectro de posibilidades. Lo mismo ocurrirá si la ley entrega pautas que permitan orientar en forma más precisa el significado de las normas señaladas. Así, el proyecto de ley que modifica la Ley Orgánica Constitucional del Congreso Nacional', en actual tramitación, contiene un párrafo específico que se reficrc a los tratados internacionales, pero que en sus distintas etapas ha sufrido varios cambios, de manera que mientras no esté totalmente afinada. preferimos no considerar.

Aś́, en este trabajo, haremos una primera aproximación respecto del contenido de las nuevas normas del arcículo 54 , que en relación a los trarados tienen varias novedades y dudas, según se verá.

Para dar una mirada general al tema diremos que, referencias a los tratados encontramos

Shagister en Derecho, Profesora de Derecho

Internacional, Universidad de Valparatio. en 5 artículos de la nueva Constitución, estos son los siguientes: $5^{\circ}, 32^{\circ}, 54^{\circ}, 93^{\circ} \mathrm{y}$ artículo decimoquinto transitorio.

Boletin $\mathrm{N}^{n} 3962-07$. 
La norma predecesora del artículo 54, que es la que comentaremos, básicamente, estaba contenida en el Art. 50 y era del siguiente tenor:

Atribuciones exclusivas del Congreso.

Artículo 50

1) Aprobar o desechar los tratados internacionales que le presentare el Presidente de la República antes de su ratificación. La aprobación de un tratado se someterá a los trámites de una ley.

Las medidas que el Presidente de la República adopre o los acuerdos que celebre para el cumplimiento de un tratado en vigor no requerirán de nueva aprobación del Congreso, a menos que se trate de materias propias de ley.

La norma en su brevedad entregaba varias dudas, en relación a su alcance y otras tantas en relación a su silencio. Hoy varias instituciones que antes no etan mencionadas son reguladas expresamente, aunque no con la claridad deseable, a nuestro juicio.

La norma actual es mucho más extensa y es ta que analizaremos a continuación, de acuerdo a las instituciones que trata:

\section{II.- Aprobación de los tratados}

a.- La intervención del Congreso se mantiene.

Dice el $n^{\circ} 1$ del actual artículo 54 , en su inciso primero, que una de las atribuciones exclusivas del Congreso es:

"Aprobar o desechar los tratados internacionates que le presentare el Presidente de la República antes de su ratificación".

Esta primera parte no sufrió modificación y está así, prácticamente desde la constitución de $1933^{2}$, donde al Congreso le cabe sólo aprobar o desechar, sin poder alterar el texto del mismo.

b.- Se especifican los quoórum para la aprobación de los tratados. Algunas dudas.

En seguida, el primer inciso del $\mathrm{N}^{\circ} 1$, del Arr. 54, continúa con la siguiente frase:

2 El Art. 82 de la Constitución de 1833, contenía las atribuciones especiales del Presidente y su $\mathrm{N}^{\circ} 19$, contemplaba la facultad de conctuir y firmar uratados y serialaba que: "Los tratados, antes de su ratificación, se presentarín a la aprobación del Congreso".

Por su parte de C.tonstinucion de 1925 disponía en su Art. $43 \mathrm{~N}^{\circ} 5$, como una de las arribuciones cxclusivas del Congreso: "Aprobar o desechar los tratados que le presentare el Presidente de la República antes de su ratiflicatión".

"Todos estos acuerdos tendrán en el Congreso los mismos rxámires de una ley". 
"La aprobación de un tratado requerirá, en cada Cámara, de los quórum que corresponda, en conformidad al artículo 66, y se someterá, en lo pertinente, a los trámites de una ley".

Aquí, en materia de quórum tenemos los primeros cambios, cuya trascendencia salta a la vista por cuanto significa agregar una mayor dificultad para la aprobación de los tratados, lo que podríamos interpretar, en términos generales, como un aumento en la barrera de entrada del Derecho Internacional convencional a nuestro ordenamien to jurídico interno, la que ahora requiere consensos más amplios del órgano político.

La cuestión de los quórum, había sido motivo de discusión en la última época y fue llevado al Tribunal Constitucional en varias oportunidades. El citado Tribunal, sin mediar norma alguna, había comenzado a considerar esta tesis, llegando a la conclusión de que se podía dividir la aprobación del tratado, de acuerdo al contenido de las normas de cada artículo, de esta manera unos artículos podían aprobarse con et quórum de una ley simple y otros necesitaban para su aprobación quórum especiales dependiendo del contenido de dichas normas. En este sentido pueden verse los fallos sobre las siguientes cuestiones: Convenio 169 de la OIT sobre Pueblos Indígenas y Tribales en Países Independientes ${ }^{3}$, Tribunal Penal Internacional ${ }^{4}$, Convención Interamericana sobre Desaparición Forzada de Personas, entre otross.

Ahora bien, la nueva norma del actual artículo 54.1, citada, se remite al artículo 66, que no ha sido modificado (anterior Art. 63), y que se refiere precisamente a los quórum de aprobación de las distintas categorías de leyes, en los siguientes términos:

Art. 66. "Las normas legales que interpreten preceptos constitucionales necesitarán, para su aprobación, modificación o derogación, de las tres quintas partes de los diputados y senadores en ejercicio.

Las normas legales a las cuales la Constitución confere el carácter de ley orgánica constitucional requerirán, para su aprobación, modificación o derogación, de las cuatro séptimas partes de los diputados y senadores en ejercicio. Las normas legales de quórum calificado se estableccrán, modificarán o derogarán por la mayoría absoluta de los dipurados y senadores en ejercicio. Las demás normas legales requerirán la mayoría de los miembros presentes de cada Cámara, o las mayorías que sean aplicables conforme a los artículos 68 y siguientes". 
De la lectura del artículo se establece la siguiente posible clasificación:

- Leyes interpretativas de la Constitución: requieren para su aprobación de las $3 / 5$ partes de los diputados y senadores en ejercicio.

- Leyes orgánicas constitucionales (LOC): requieren para su aprobación las $4 / 7$ partes de los diputados y senadores en ejercicio.

- Leyes de quórum calificado: requieren para su aprobación la mayoría absoluta de los diputados y senadores en ejercicio.

- Las demás normas legales (leyes simples): requerirán la mayoría de los miembros presentes de cada Cámara.

- Leyes que requieren quórum especiales en su tramitación debido a su rechazo en la Cámara de origen: las mayorías que sean aplicables conforme a los artículos $68 \mathrm{y}$ siguientes.

Algunas de las dudas que nos surgen al respecto son las siguientes:

Como el artículo 66, recién citado hace una remisión al artículo 68 y siguientes, éstos deben analizarse para determinar en qué medida ellos son aplicables a los tratados.

Dice el artículo 68:

"El proyecto que fuere desechado en general en la Cámara de su origen no podrá renovarse sino después de un año. Sin embargo, el Presidente de la República, en caso de un proyecto de su iniciariva, podrá solicitar que el mensaje pase a la otra Cámara y, si ésta lo aprueba en general por los dos tercios de sus miembros presentes, volverá a la de su origen y sólo se considerará desechado si esta Cámara lo rechaza con el voto de los dos tercios de sus miembros presentes".

Nos parece que esta hipótesis hoy es aplicable a los tratados y por lo tanto estos quórum también interesan en la materia. A pesar de que en la antigua norma ello no era posible, la situación cambió, y se han abierto nuevas posibilidades para los tratados, y mientras no exista una ley interpretativa no hay más límites que los impuestos por la práctica en ejercicio del texto antiguo, que hoy debemos empezar a renovar.

Estimamos que los artículos 69,70 y 71 , en principio, no son pertinentes a la aprobación de los tratados por cuanto se refieren a las adiciones o correcciones que es posible hacer a los proyecros de ley, lo que en el caso de un tratado, que es un texto que viene dado desde una fuente externa, no corresponde.

En el caso de la comisión mixta, tratada en el artículo 70 , nos queda la duda si ella podía formarse para solucionar discrepancias respecto de las reservas, por ejemplo. Más adelante volveremos sobre el tema. 
El resto de los artículos citados genéricamente por el arrículo 66, esto es, desde el 72 al 75 tampoco nos parecen pertinentes en esta parte, en que nos estamos refiriendo exclusivamente a los quórum para la aprobación en ambas Cámaras de un tratado.

Otro de los puntos en que nos han surgido dudas, es en la norma transitoria decimoquinta que se refiere a esta cuestión, para resolver la situación de los tratados ya vigentes en los siguientes términos:

"Los tratados internacionales aprobados por el Congreso Nacional con anterioridad a la entrada en vigor de la presente reforma constitucional, que versen sobre materias que conforme a la Constitución deben ser aprobadas por la mayoría absoluta o las cuatro séprimas partes de tos diputados y senadores en ejercicio, se entenderá que han cumplido con estos requisitos"6.

La norma hace alusión sólo a dos especies de quórum:

- la mayoría absoluta que es el quórum requerido para la aprobación de las leyes de quórum calificado, $y$

- las cuatro séptimas partes que es aquel quórum necesario para la aprobación de las leyes orgánicas constitucionales.

Nos preguntamos entonces: ¿Qué pasa con los demás?

Qué pasa con los tratados ya aprobados que, por ejemplo, de alguna manera, se entiende interpretan preceptos constitucionales (que también es una hipótesis que contempla el artículo 66, expresamente citado en el actual Art. 54.1), y cuyo quórum de aprobación es de las tres quintas partes de los diputados y senadores en ejercicio? Lo mismo ocurre con el resto de los quórum establecidos en el artículo 68 y siguientes, citados a su vez por el Art. 66 .

No nos arriesgamos, por el momento, a explicar este punto y sólo lo dejamos planteado, pues advertimos allí un vacío. A nuestro modo de ver, quizás la norma debió ser más genérica, pues siempre puede surgir una hipótesis que no calce exactamente con la figura tan acotada descrita en la norma transitoria.

c.- Trámites para la aprobación del tratado. Persiste la incógnita.

La última frase del inciso primero del Art. 54.1, dispone, en relación a la aprobación del tratado, que además de respetar los quórum indicados, debe someterse "en lo pertinente, a los trámites de una ley".

- La redacción definitiva de la norma corresponde a las observaciones planteadas par el Presidente de la República (Veco $\mathrm{N}^{\circ} 24$ ). 
Aquí también tenemos una innovación ${ }^{7}$, cuyo objeto fue zanjar la vieja disputa en relación a cuáles trámites requería someterse el tratado para entenderse aprobado, esto es a todos los trámites en forma idéntica a la ley, o sólo a aquellos que debía seguir la ley en el Congreso, que era él ámbito en que se insertaba la norma, ya que el párrafo donde está inserto se titulaba y aún se titula, precisamente, como "Atribuciones exclusivas del Congreso".

El problema se presentaba en varios ámbitos. En lo más grueso el tema se discutía respecto de si la promulgación y publicación del tratado eran trámites necesarios para que éste se entendiera aprobado y vigente en Chile, puesto que estos trámites sí tenian ese efecto respecto a la ley.

También llegó a discutirse si el control de constitucionalidad establecido en el antiguo Art. 82.1 era un trámite posible en ei caso de los tratados ${ }^{6}$, cuestión que hoy se encuentra expresamente contemplado en el actual Art. 93.1.

El cambio de redacción con el agregado de la frase "en lo pertinente", al menos nos aclara que los tratados no seguirán todos los trámites de la ley sino sólo los pertinentes de acuerdo a su naturaleza. Nuestro trabajo, en su momento, será analizar, entonces, cuáles trámites son pertinentes o no, cuestión que debe verse artículo por artículo y previendo todas las situaciones posibles que pueda sufrir un tratado, siguiendo la misma ruta de aprobación de la ley.

Por lo menos debemos afirmar que estos "trámites pertinentes" deben ser sólo aquellos que se den mientras el tratado se encuentre en la etapa de aprobación en el Congreso y no aquellos que debe seguir la ley fuera del mismo, como la promulgación y la publicación, cuyo efecto se vincula con el tema de la presunción de conocimiento de la norma, pero no con la vigencia del tratado en el orden interno, pues ni la Constitución ni la ley dicen nada al respecto. Por ello bastará con su aprobación en el Congreso, con los quórum que ahora se han establecido y los demás trámites que en la misma Constitución se señala -como el control de Constitucionalidad, en su caso-, para que los tratados se entiendan aprobados y vigentes en el orden interno.

Sobre el tema de la promulgación y publicación de los tratados quizás es conveniente citar la norma que existió durante el Gobierno militar que contribuyó a crear el mito de la obligatoriedad de la promulgación y publicación.

\footnotetext{
La Constinción de 1980 en su Art. $50 \mathrm{~N}^{\circ} \mathrm{l}$, disponia al respecro: "La aprobación de un tratado se somererd a los trámites de una loy".

Por su parte la Constitución de 1925 señalaba en el Arr. 43, No 5: "Todos entos acuetios tendrán en el Congreso los mismos tramizes de tind tey".

F'ot su parte la Constikución de 1833, no se referia a los trámites pertinentes a la aprobación del tratado por el Congreso.

* Ver Roil 309 del Tribunal Constirucional que recavó en el Convenio 169 de la OIT.
} 
Nos referimos al Decreto Ley $N^{\circ} 247$, de 1973 que establecía "normas para la suscripción, aprobación, ratificación y promulgación de los tratados internacionales".

El artículo $3^{\circ}$ disponía, a propósito de la aprobación, lo siguiente: "una vez suscrito un tratado, éste será sometido a la aprobación de la Junta de Gobierno, la que lo hará mediante la dictación de un Decreto Ley.

Luego el artículo $5^{\circ}$ señalaba que "Una vez que se haya efectuado el canje o el depósito de los instrumentos de ratificación o adhesión, según el caso, el tratado deberá ser promulgado por decreto supremo del Ministerio de Relaciones Exteriores, que ordenará que este se cumpla y lleve a efecto como ley de la República y que tanto dicho decreto supremo como el texto del tratado se publiquen en el Diario Oficial".

A pesar de que el citado decreto $\mathrm{N}^{\circ} 247$ de 1973, fue derogado formalmente recién en el año $1990^{\circ}$, creemos que desde la vigencia de la Constitución de 1980, ya había sido derogado tácitamente, pues corresponde al Congreso, por mandato constitucional, aprobar los tratados. Aun así, el uso, en relación a la promulgación y publicación de los tratados, se ha mantenido en similar forma.

Para graficar lo indicado citamos como ejemplo los decretos promulgatorios de los siguientes tratados que hemos elegido al azar:

a) Decreto Supremo $N^{\circ} 214$ del Ministerio de Relaciones Exteriores (Diario Oficial de fecha 30 de octubre de 2003) que Promulga el Convenio Cultural Básico con la República Árabe Siria.

Artículo único: Promúlgase el Convenio Cultural Básico entre el Gobierno de la República de Chile y el Gobierno de la República Árabe Siria, suscrito el 15 de febrero de 1990; cúmplase y llévese a efecto como ley y publíquese copia autorizada de su texto en el Diario Oficial.

b) Decreto Supremo No 195 del Ministerio de Relaciones Exteriores (Diario Oficial de fecha 7 de enero de 2006), que Promulga el Memorándum de Entendimiento con Malasia sobre cooperación en el ámbito de la información.

Articulo único: Promúlgase el Memorándum de Entendimiento con Malasia sobre cooperación en el ámbito de la información suscrito entre el Gobierno de la República de Chile y el Gobierno de Malasia el 18 de mayo de 1993;

9. Ta ley 18.903 publicada en el Diario Oficial con fecha 19 de enero de 1990, en su arículo único, en el número 9. derogó, cntrc otros, el Decreto $N^{\circ} 247$ de 1973. 
cúmplase y llévese a efecto como ley y publíquese copia autorizada de su texto en el Diario Oficial ${ }^{10}$.

En el orden internacional la cuestión de la obligatoriedad del tratado está regulada en la Convención de Viena sobre el Derecho de los Tratados", que en último tétmino se remite a lo que las Partes hubieren convenido en el mismo tratado.

Ahora bien, la exposición de motivos de la moción que dio origen a la reforma constitucional (Boletín $\mathrm{N}^{\circ} 2526-07$ ), no traía la norma del actual artículo 54 en la forma que está hoy, por lo que en cuanto a los "trámites pertinentes" no encontramos una explicación del sentido de la reforma, ya que ella fue agregada en el transcurso de la tramitación del proyecto.

Creemos que la frase no viene sino a explicitar una situación obvia, pues aun antes de ella no podía someterse a los tratados a trámites que, por su naturaleza, no fueran pertinentes, como es el caso de las adiciones o correcciones que pueden hacer las Cámaras a los proyectos de ley y que pueden dar origen a una comisión mixta, pero que nunca podrán hacerse a los tratados que vienen dados desde una fuente externa. En este sentido no es mucho el aporte pues seguirá siendo fruto de especulación doctrinaria determinar cuáles son estos trámites 'pertinentes'.

\section{III.- Las Reservas}

La Convención de Viena sobre el Derecho de los Tratados señala que se entiende por "reserva" una declaración unilateral, cualquiera que sea su enunciado o denominación, hecha por un Estado al firmar, ratificar, aceptar o aprobar un tratado o al adherirse a él, con objeto de excluir o modificar los efectos jurídicos de ciertas disposiciones del tratado en su aplicación a ese Estado (Art. 2, lerra "d"). Luego en sus artículos 19 al 23 regula con más detalle algunos aspectos jurídicos vinculados a ellas, a su retiro, a las objeciones y procedimientos.

En nuestro ordenamiento jurídico conocemos importantes reservas que siempre se tienen presente por cuanto significan importantes limitaciones a las obligaciones impuestas por et tratado, citamos como ejemplo el Código de Derecho Internacional Privado, donde la reserva hecha por nuestro país lo convierte sólo en norma supletoria y la Convención Americana de Derechos Humanos que contiene una limitación

Iu Nos han serialado, desde Cancillería, que el decreto es antiguo, a pesar de su fecha de publicación y que los acruales decretos ya no traen la frase que se remire a la ley.

"Aprelkada en Chile por Decreto Supremo $N^{\circ} 381$ del Ministerio de Relaciones Exteriores, publicado en el Diario Oficial de fecha 22 de junio de 1981. 
temporal ${ }^{12}$, que a propósiro de una reciente sentencia de la Corte Interamericana ${ }^{13}$ se ha discutido su vigencia. La misma Convención de Viena fue aprobada con reserva por nuestro país.

Veremos a continuación las normas que introdujo la reforma sobre esta materia.

\section{a. Formulación de reservas por parte del Presidente de la República}

La nueva norma constitucional señala al respecto en el artículo 54.1, inciso $2^{\circ}$, lo siguiente:

El Presidente de la República informará al Congreso sobre el contenido y el alcance del tratado, así como de las reservas que pretenda confirmar o formularle.

Ahora bien el momento en que el Presidente debe informar al Congreso respecto de las reservas que pretenda confirmar o formularie, no está expresamente señalado, pero esto debería ser conjuntamente con la presentación del tratado, o sea en el mensaje. No se descarta que esto también pueda hacerse en otro momento, en el transcurso de la tramitación, e incluso mediante una indicación en ejercicio de la facultad del artículo $73^{14}$, respecto de una reserva sugerida por el Congreso con el objeto de conseguir un consenso respecto de los términos de la misma. Sabemos que el Presidente es quien en definitiva decide sobre la reserva y que el Congreso sólo puede "sugerir", según se verá, pero nada obsta a que el Primer Mandatario quiera lograr un acuerdo, sobre

12 Dice la declaración de Chile respecto de la competencia de la Comisión y de la Corte Inecramericana:

“a) El Ciobierno de Chile declara que reconoce la competencia de la Comisión Interamericana de Defechos Humanos, por tiempo indefinido y bajo condiciones de reciprocidad, para recibir y examinar las comunicaciones en que un Estado Parte alegue que otro Escado Parte ha incurrido cn violaciones de derechos humanos establecidos en la Convención Americana sobre Derechos Humanos, en lns términos peevisros en el artículo 45 de la mencionada Convención.

b) Fl gobierno de Chile declara que reconoce como obligatoria de pleno derecho la competencia de la Corte Inceramericana de Derechos Humanos respecto de los casos relarivos a la interpretación y aplicación de esia Camvención de conformidad con lo que dispone su articulo 62 .

Al formular las mencionadas Declaraciones, el Gobierno de Chile deja conscancia que las teconocimientos de competencia que ha conferillo se refieren a hechos posteriores a la fecha del deprósito de este Instrumento de Ratificación o, en todo caso, a hechos cuyo principio de cjecución sea posterior al ll de marzo de 1990 . Igualmente el Gobierno de Chile, al conferir la competencia a la Comisión y a la Corre Interamericana de Detechos Humanos, declara que estos órganos, al aplicar lo precepruado en el párrafo segundo del articulo 21 de la Convención, no podrán pronunciarse acerca de las razones de urilidad pública o de interés sectial que se havan renido en consideración al privar de sus bienes a una persona".

13. Corte IDH. Caso Almonacid Arelliano y ouros vs. Chile. Sentencia sobre Excepciones Preliminares, Fondo, Reparaciones y Cosras. Sentencia de 26 de septiembre de 2006 Serie C. No. 154.

Los hechos expuesros por la Comisión en la demanda se refieren a la presunta falta de investigación y sanción de los responsabies de la cjecución extrajudicial del seńor Almonacid Arellano, a partir de la aplicación del Decreto Ley No. 2.191, ley de amristia, adoptada en 1978 en Chile, asi como a la supuesta falta de reparación adecuada a favor de sus familiares.

14 El articulo 73 en sus incisos $1^{\circ} \mathrm{y} 2^{\circ}$ dispone lo siguiente:

Arriculo 73.- Si el Presidente de la República desaprueba el proyecto, lo devolverá a la Cámara de su origen con las obscrvaciones convenientes, dentro del término de rreinta dias.

Fn tringúfn case se admirírán las obseryaciones que no tengan relación direcra con las ideas matrices o fundamentales del proyecro, a menos quc hubieran sido considemadas en el mensaje respectivo. 
todo si se trata de cuestiones de alta sensibilidad donde un actuar autosuficiente suyo podría significarle un alto costo político frente a la comunidad; así este acuerdo con et Congreso, sobre la reserva, podría ser obtenido a través del veto.

Aquí nos surge una duda en el sentido de si esta reserva podría ser informada por el Presidente de la República inctuso luego de aprobado el tratado por el Congreso. Estimamos que ello no es posible. Aunque técnicamente la norma quizás lo permita, habría una actuación de mala fe, al dejar que el Congreso apruebe el tratado sin tener en vista la reserva que, luego, el Presidente haga. Además, hay que tener presente que toda la regulación del artículo 54 es para el momento en que el tratado se encuentra en el Congreso, y una hipótesis como la cuestionada se estaría dando cuando el tratado ya está fuera del Congreso porque éste ya fue aprobado.

\section{b.- Reservas propuestas por el Congreso}

Esta hipótesis está contemplada en la reforma en los siguientes términos:

El Congreso podrá sugerir la formulación de reservas y declaraciones interpretarivas a un tratado internacional, en el curso del trámite de su aprobación, siempre que ellas procedan de conformidad a lo previsto en el propio tratado o en las normas generales de derecho internacional.

Ahora bien podría ser que no exista acuerdo entre las Cámaras respecto de la "reserva sugerida", lo que en opinión de la suscrita podría dar origen a una comisión mixta de aquellas señaladas en el artículo 70, la que no podría formarse para solucionar discrepancias respecto del texto del tratado, el que no puede tener modificacioncs, pero sí respecto de las reservas o declaraciones interpretativas, pues si no, ¿cómo se resuelve la discrepancia?

\section{c.- Retiro de la reserva}

El inciso $8^{\circ} \mathrm{del}$ artículo 54.1 , dispone lo siguiente:

El retiro de una reserva que haya formulado el Presidente de la República y que tuvo en consideración el Congreso Nacional al momento de aprobar un tratado, requerirá previo acuerdo de éste, de conformidad a lo establecido en la ley orgánica constitucional respecriva. El Congreso Nacional deberá pronunciarse dentro del plazo de treinta días contados desde la rccepción del oficio en que se solicita el acuerdo pertinente. Si no se pronunciare dentro de este término, se tendrá por aprobado el retiro de la reserva.

Entendemos entonces que una reserva que no tuvo en consideración el Congreso al momento de aprobar cl tratado no requiere acuerdo de éste para su retiro.

En el caso de las reservas que sí tuvo en consideración el Congreso se produce una situación no equivalente respecto de la formulación de la misma, donde en esta última 
hipótesis al Congreso le cabe sólo sugerirla, en cambio para su retiro es necesario el acuerdo de la Corporación.

\section{d- Norma de publicidad}

También se ha incorporado una nueva norma en relación a la publicidad de los distintos hechos vinculados con la vigencia de los tratados, donde se alude también a las reservas en los siguientes términos.

De conformidad a lo estabłecido en la ley, deberá darse debida publicidad a hechos que digan relación con el tratado internacional, tales como su entrada en vigot, la formulación y retiro de reservas, las declaraciones interpretativas, las objeciones a una reserva y su retiro, la denuncia del tratado, el retiro, la suspensión, la terminación y la nulidad del mismo.

Para la forma en que se hará esta publicidad hay una remisión genérica a la ley, suponemos que esta forma no puede ser otra que la publicación en el Diario Oficial de todas las situaciones enumeradas, vinculadas con la vigencia y efectos de los tratados. Estimamos que esta cuestión de la publicidad debió ser más explicita, y, a nuestro juicio, publicidad y vigencia interna deberían ir de la mano, como en el caso de la ley, con plazos determinados para ellos, lo que contribuiría a una mayor seguridad jurídica.

Hacemos presente también que la ley $\mathrm{N}^{0} 18.158^{15}$, establece normas sobre publicación de los tratados, pero sólo se refiere a aquellos de gran volumen o extensión, cuya publicación podrá efectuarse mediante el depósito de un ejemplar en el Ministerio de Relaciones Exteriores y de otro en la Contraloría General de la República debidamente autenticados $^{16}$. Se exceptúan de esta norma los tratados sobre fronteras o límites, o que puedan afectar la integridad territorial del Estado.

\section{IV.- Alteración de los tratados}

\section{a.- Modificación de un tratado}

Sobre esta cuestión es que se han producido los mayores cuestionamientos de los profesores de Derecho Internacional ${ }^{17}$, por lo determinante de la nueva norma respecto de la superioridad del Derecho Internacional sobre el Derecho Interno. Veamos la norma del artículo 54,1, inciso $5^{\circ}$.

15 Publicada en el Diario Oficial de fecha 9 de sepriembre de 1982.

16 Lna copia del tratado se remirirá cambićn a cada una de las oficinas regionales de la Conraloría (Art. 2).

:- El rema fue debatido precisamente en el seno de la Suciedad de Derecho Internacional en reunión de fecha 29 de agosto de 2005, sobre "Los tratados internacionales antc la reforma constitucional en Chile". 
Las disposiciones de un tratado sólo podrán ser derogadas, modificadas o suspendidas en la forma prevista en los propios tratados o de acuerdo a las normas generales de derecho internacional.

Se ha estimado que aquí hay una importante renuncia de soberanía en el sentido de que una norma interna, cualqujera sea su categoría, jamás podrá alterar un tratado, sea para derogarlo, modificarlo o suspenderlo pues eilo sólo puede ocurrir en la forma prevista en el propio tratado o de acuerdo a las notmas generales del Derecho Internacional, con lo que queda de manifiesto la preeminencia del Derecho Internacional sobre el Derecho Interno.

Algunos han estimado que esta norma ya estaba contemplada en nuestro ordenamiento jurídico interno, por cuanto el artículo $27 \mathrm{de} \mathrm{la} \mathrm{Convención} \mathrm{de} \mathrm{Viena} \mathrm{sobre} \mathrm{el} \mathrm{Derecho}$ de los Tratados, vigente en Chile, la contempla en los siguientes términos:

\section{Articulo 27}

El derecho interno y la observancia de los tratados

Una parte no podrá invocar las disposiciones de su derecho interno como justificación del incumplimiento de un tratado. Esta norma se entenderá sin perjuicio de lo dispuesto en el artículo 46 (sobre nulidad de los tratados).

Estimamos, sin embargo que la norma citada dice relación con un tema de responsabilidad del Estado, en el sentido de que el Estado no podrá invocar su Derecho lnterno como justificación del incumplimiento, o sea invocar su Derecho Interno no le exime de ta responsabilidad, pero no dice que el Estado renuncia a que mediante una norma interna se altere un tratado, como sí se hizo en nuestra Constitución.

De esta forma coincidimos con la opinión que señala que nuestra Constitución fue más allá y renunció a toda posibilidad de alterar un tratado mediante una norma de Derecho Interno.

\section{b.- Denuncia}

Esta norma también es nueva, pues si bien siempre se estimó que el Presidente de la República tenía la facuitad de denunciar los tratados en virtud de la disposición que lo señala como conductor de las relaciones políticas con las potencias extranjeras, ahora se requiere un nuevo requisito como es la intervención del Congreso, en los siguientes términos (Art. 54.1, inciso $6^{\circ}$ ):

Corresponde al Presidente de la República la facultad exclusiva para denunciar un tratado o retirarse de él, para lo cual pedirá la opinión de ambas Cámaras del Congreso, en el caso de tratados que hayan sido aprobados por éste. Una vez que la denuncia o el retiro produzcan sus efectos en conformidad a lo establecido en el tratado internacional, éste dejará de tener efecto en el orden jurídico chileno. 
En primer lugar, se trata de pedir una opinión, la cual no sería vinculante para el Presidente. Por otra Parte se trata de pedir la opinión y no de obtenerla, de manera que entendemos que el requisito se cample con et mero hecho de pedir la opinión, independientemente de que esta efectivamente se dé y del contenido de la misma. Ello se confirmaría por el hecho de que no se establece ningún procedimiento para obtener esta opinión, ni un plazo.

Además, nos surge ła duda, en está hipótesis, si es posible la formación de una Comisión Mixta en caso de que no haya acuerdo en las Cámaras sobre el contenido de la opinión en cuestión. Pues si no, ¿cómo se resuelve la discrepancia entre las Cámaras? Habrá que inventar un nuevo procedimiento?

Adicionalmente, debemos agregar que sólo es necesaria la opinión del Congreso respecto de la denuncia o retiro de tratados que hubieren sido aprobados por éste; de esta forma, según el tenor de la norma, se excluyen aquellos tratados aprobados en los periodos de nuestra historia donde no ha habido Congreso. En esta situación, debemos incluir, entonces, desde ya, todo el periodo del Gobierno Militar que va desde 1973 a 1990 , donde no hubo Congreso.

Debemos recordar que la Constitución de 1980 estableció que la Junta de Gobierno, integrada por los más altos mandos de las Fuerzas Armadas y Carabineros, eran quienes ejercían el Poder Legislativo ${ }^{18}$, lo que no es equivalente a Congreso, que es el término que usa la nueva norma y que, según la RAE, en la acepción que nos interesa, se define de la siguiente manera: "Con arreglo a algunas Constituciones de España e Hispanoamérica, cuerpo legislativo compuesto de personas nombradas directamente por los electores".

También se incluirian en esta hipótesis los acuerdos en forma simplificada o informales.

Por último la frase final del inciso $6^{\circ}$ citado, señala que una vez que la denuncia o el retiro produzcan sus efectos en conformidad a lo establecido en el tratado internacional, éste dejará de tener efecto en el orden jurídico chileno. Esto apoya la tesis de que la promulgación y publicación no son trámires vinculados con la vigencia interna del tratado y que son simples medidas de publicidad, las que sin embargo, en nuestra opinión deberían ir conectadas.

Continúa el inciso $7^{\circ}$ con la siguiente disposición:

En el caso de la denuncia o el retiro de un tratado que fue aprobado por el Congreso, el Presidente de la República deberá informar de ello a éste dentro de los quince días de efectuada la denuncia o el retiro.

18 Articulo decimonoveno transitorion de la Constituciśn de 1980. 
Entendemos que esta es una norma de publicidad que también opera sólo respecto de aquellos tratados en cuya aprobación debió intervenir el Congreso, y por lo tanto para su denuncia también hubo de pedir su opinión. Ahora bien, no entendemos muy bien la lógica de estas normas, pues en vez de admitir una participación igual del Congreso respecto de todos los tratados, y más aun respecto de aquellos en cuya aprobación no intervino, se deja a estos tratados excluidos, tanto del trámite de la consulta u opinión establecida en el inciso $6^{\circ}$, como de la información aludida en el inciso $7^{\circ}$, en el sentido de haberse efectuado la denuncia o el retiro.

\section{V.- Otras facultades del Presidente de la República en el ámbito internacional}

En esta categoría hemos considerado tres tipos de instrumentos que permiten al Presidente de la República actuar en el ámbito internacional.

\section{a.- Acuerdos de ejecución. Sin modificación.}

Este tipo de acuerdos ya estaba previsto en la antigua norma de la Constitución de 1980 y no sufrió cambios con la reforma, sólo el cambio de lugar del inciso $4^{\circ}$ del actual artículo 54 .l, según se verá:

Las medidas que el Presidente de la República adopte o los acuerdos que celebre para el cumplimiento de un tratado en vigor no requerirán de nueva aprobación del Congreso, a menos que se trate de materias propias de ley.

\section{b.- Acuerdos vinculados a materias propias de la potestad reglamentaria. Se explicita esta facultad del Presidente de la Repuiblica.}

Esta cuestión es nueva, donde una frase agregada en la reforma complementó la norma originaria del actual inciso $4^{\circ}$, explicitando está facultad del Presidente de la República en los siguientes términos:

No requerirán de aprobación del Congreso los tratados celebrados por el Presidente de la República en el ejercicio de su potestad reglamentaria.

Nos parece conveniente la frase, a pesar de que creernos que el Presidente de la República siempre debió poder actuar en el ámbito propio de su competencia, aun cuando fuera en una acrividad internacional, pero como al parecer la Contraloría General de la República no opinaba lo mismo, es de toda conveniencia la aclaración.

\section{c. - Decretos con fuerza de ley. Sin modificación.}

Esta posibilidad que ya estaba contemplada en la norma antes de la reforma 2005, no sufrió modificaciones, manteniéndose en idénticos términos, según se verá: 
En el mismo acuerdo aprobatorio de un tratado podrá el Congreso autorizar al Presidente de la República a fin de que, durante la vigencia de aquél, dicte las disposiciones con fuerza de ley que estime necesarias para su cabal cumplimiento, siendo en tal caso aplicable lo dispuesto en los incisos segundo y siguientes del artículo 64 .

\section{V.- Síntesis y conclusiones}

El artículo 54.1 que aquí hemos comentado preliminarmente, incorpora una serie de normas que nunca antes se habían considerado en forma expresa en ninguna de nuestras Constituciones.

Junto con incorporar nuevas funciones del Congreso en materia de aprobación de los tratados, explicita algunas cuestiones que con el uso se habian ido consagrando en nuestro ámbito jurídico.

Sin embargo, estimamos que la reforma no fue lo suficientemente precisa en el sentido de no regular una serie de aspectos respecto del funcionamiento de algunos procedimientos que allí se señalan y persistirán las dudas respecto de la obligatoriedad o efecto de ciertos actos como es la promulgación y publicación del tratado, la formación de comisiones mixtas, en determinadas circunstancias, o algún otro mecanismo que permita resolver las discrepancias entre las Cámaras, pues no parece conveniente que una Cámara vete a la otra sin más trámite, la alteración de tratados ya vigentes aprobados en periodos de irregularidad parlamentaria, la preeminencia del Derecho Internacional en determinadas hipótesis, etc.

Creemos que sobre esta norma se escribirá y comentará bastante más aún, en la medida que las distintas hipótesis se vayan dando y en la medida en que las instituciones involucradas resuelvan dichos temas.

Una tarea importante le queda a la ley para ir acotando las normas recientemente inauguradas. 
